\title{
INFLUENCE OF THE PHOTOPERIOD ON THE OIL PERCENTAGE OF SESAME SEEDS (Sesamum indicum L.)')
}

\author{
H. KLUIJVER and K. W. SMILDE \\ Laboratory of Tropical Agriculture, State Agricultural University, \\ Wageningen, Holland
}

\section{SUMMARY}

It appears from various publications $(1,3)$ that the oil percentage of oilseed crops rises with an increasing length of the photoperiod. This is investigated below for sesame (Sesamum indicum L.).

\section{INTRODUCTION}

The experiments were carried out in greenhouses of the Laboratory of Tropical Agriculture, Wageningen. The plants were grown in a sandy soil in 13 trucks, which could be driven into compartments of a large shed. Thirteen different photoperiods were applied, made up of a basic illumination of daylight and supplemental light from lamps, as shown in Table 1. The supplemental light in each compartment was given from two Philips 40 watt TL 55 fluorescent tubes; the light intensity at plant level, 1 metre below the lamps, was 2,000 erg. $\mathrm{sec}^{-1} \cdot \mathrm{cm}^{-2}$. The same photoperiods were maintained throughout the period from planting to harvesting. The basic illumination contained an equal number of morning and afternoon hours, so that it was concentrated at about 12 noon. Subsequently the supplemental light was given in continuation of the basic illumination.

Throughout the experiment the maximum temperatures varied from $31^{\circ}$ to $35^{\circ} \mathrm{C}$ and the minimum temperatures from $15^{\circ}$ to $20^{\circ} \mathrm{C}$. The relative humidity was in the range of 50 to $80 \%$. By circulating the air, a difference in temperature and relative humidity inside and outside the shed was avoided.

The experiment was carried out with the branching variety Early Russian (U.S.A.), which has two capsules per node. The plants were sown on 23rd April, 1959. After two cotyledons and two leaflets had developed, the plants were planted out on 29th April. After thinning, the distance apart in and between the rows was about $20 \mathrm{~cm}$.

The plants were harvested when the leaves began to fall off and the capsules grew yellow and burst open; this occurred between 30th June and 5th September, 1959, according to the photoperiod applied. The number of plants in each treatment was about 20. Of these, all capsules on the main stem were dried in air, peeled, and the seeds selected; spongy seeds were discarded. Of the amounts of seed thus obtained four 2 gram samples were taken from each treatment, viz. two samples for determining the oil percentage and two for determining the moisture content.

The oil percentage was determined by the Soxhlet extraction method. All percentages were based on dry weight. The determinations were thus duplicated, the differences between the duplicates averaging $0.2 \%$ of oil. All obser-

1) Received for publication November 18, 1959. 
vations, including the duplicates, were included in the arithmetical calculations.

\section{Results}

The results obtained in the various illuminations are shown in Table 1. The photoperiods are arranged in five groups, viz. A ( $<10$ hours), B (10 hours), C (13 hours), D (16 hours) and E (20 hours).

Table 1 Oil percentage of the seeds at different photoperiods.

\begin{tabular}{|c|c|c|c|c|c|c|c|c|c|c|c|}
\hline 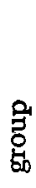 & 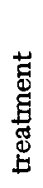 & 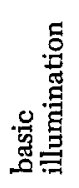 & & 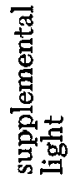 & 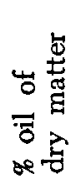 & 泀 & 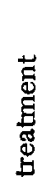 & 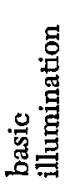 & & 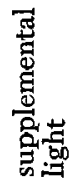 & 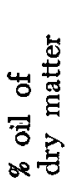 \\
\hline $\mathbf{A}$ & $\begin{array}{l}1 \\
2\end{array}$ & $\begin{array}{l}6^{\text {h }} \\
8\end{array}$ & + & $\begin{array}{l}0^{h} \\
0\end{array}$ & $\begin{array}{l}51.9 \\
51.2\end{array}$ & $\mathrm{D}$ & $\begin{array}{r}9 \\
10\end{array}$ & $8^{8 \mathrm{~h}}$ & + & $\begin{array}{l}8^{h} \\
6\end{array}$ & $\begin{array}{l}53.7 \\
54.9\end{array}$ \\
\hline B & $\begin{array}{l}3 \\
4 \\
5\end{array}$ & $\begin{array}{r}6 \\
8 \\
10\end{array}$ & $\begin{array}{l}+ \\
+\end{array}$ & $\begin{array}{l}4 \\
2 \\
0\end{array}$ & $\begin{array}{l}51.6 \\
51.2 \\
51.9\end{array}$ & $\mathbf{E}$ & $\begin{array}{l}11 \\
12 \\
13\end{array}$ & $\begin{array}{r}6 \\
8 \\
10\end{array}$ & $\begin{array}{l}+ \\
+\end{array}$ & $\begin{array}{l}14 \\
12 \\
10\end{array}$ & $\begin{array}{l}56.5 \\
57.4 \\
58.7\end{array}$ \\
\hline C & $\begin{array}{l}6 \\
7 \\
8\end{array}$ & $\begin{array}{r}6 \\
10 \\
13\end{array}$ & $\begin{array}{l}+ \\
+ \\
+\end{array}$ & $\begin{array}{l}7 \\
3 \\
0\end{array}$ & $\begin{array}{l}\mathbf{5 2 . 1} \\
\mathbf{5 2 . 9} \\
\mathbf{5 2 . 3}\end{array}$ & & & & & & \\
\hline
\end{tabular}

Table 1 shows that the treatments are classified into 5 groups, only the total time of illumination being taken into account no matter whether it consisted of daylight only or of a combination of daylight and artificial light. These groups are also summarised in Table 2, with the mean oil percentages per group and the differences between the groups.

Table 2 Average oil percentage per group of photoperiods.

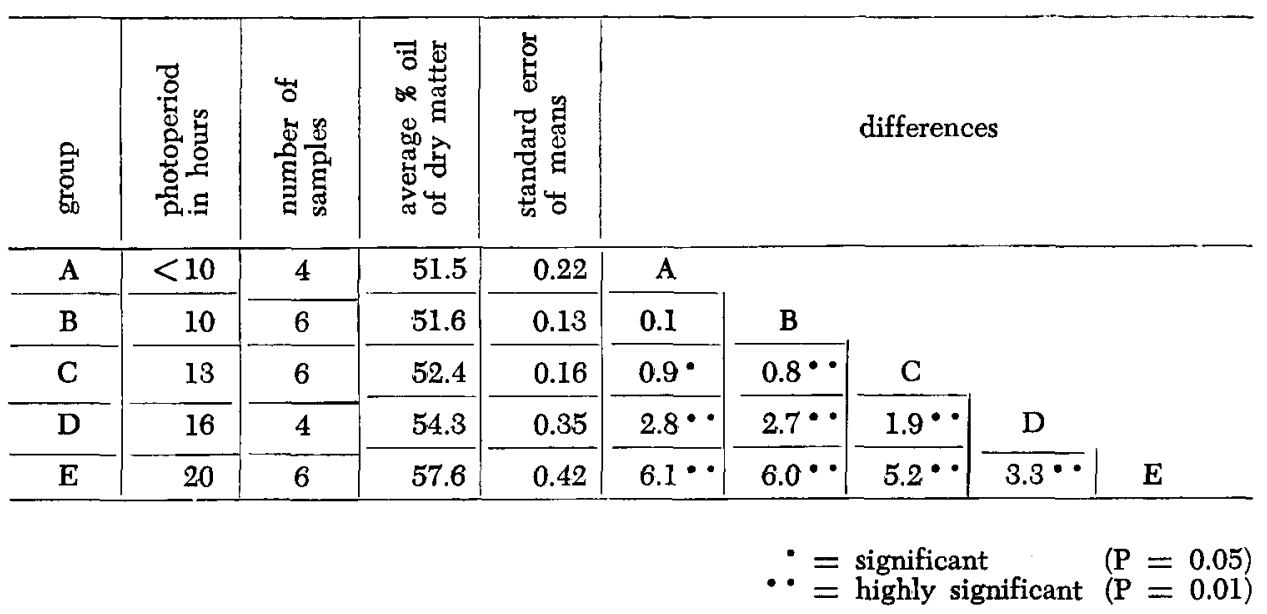


Independent of the combination of daylight and artificial light, the oil percentages were almost equal at illumination periods of 10 hours or less. When, however, the illumination was continued for longer than 10 hours there was a gradual increase in the oil percentage. The differences are significant or highly significant according to Student's t-test.

Table 1 also shows that within the groups the highest oil percentage was generally found in the treatment with the longest period of daylight as basic illumination.

In order to provide a clear survey of the results, they are again summarised below in the form of a graph.

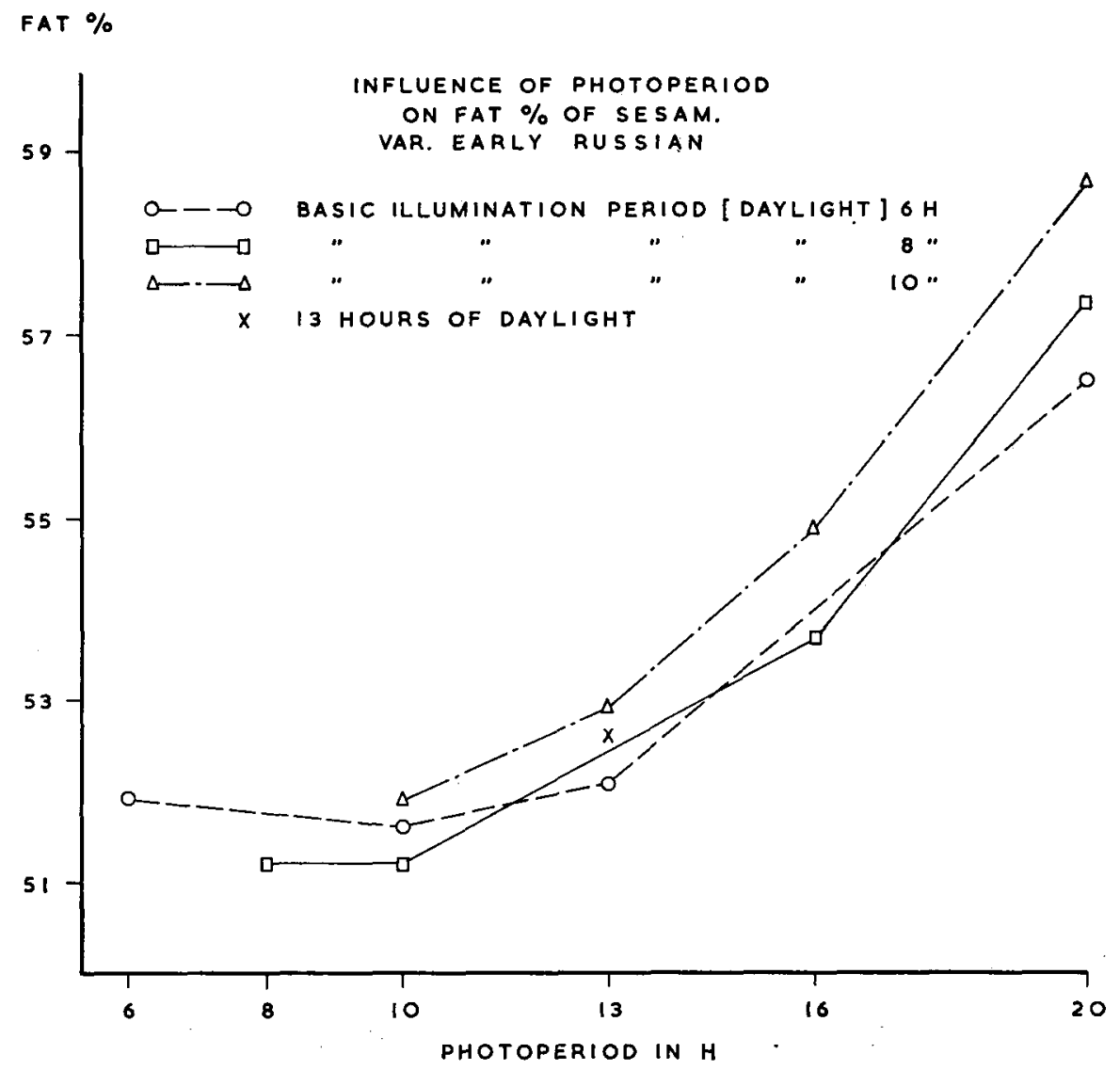

Fig. 1 EFfect of the PHOtoperiod on the oIl PERCENTAGe.

\section{Discussion}

It was demonstrated that a longer photoperiod resulted in a higher oil percentage of the seed. Light may directly influence the formation of oil, although the increase in the oil percentage may also be connected with the more vigorous development of the plant. As a matter of fact plants receiving for instance 20 hours of light will show a more vigorous vegetative development than those grown at a 6-hour photoperiod. 
The increase in the oil percentage with a longer supplemental illumination with weak light is probably due to the more vigorous vegetative development of the plants. Generally speaking it was found that the maximum oil percentage within the groups of photoperiods of equal length occurred with the longest basic illumination.

Although there are very few references in literature as regards the relation between photoperiod and quality of seeds in general, they usually indicate that the oil percentage increases with lengthening photoperiods.

KurNIK (3) performed experiments in which he imitated the daylength conditions of various latitudes by means of supplemental light and darkening. $\mathrm{He}$ found that the oil percentage increased and the protein content decreased at higher latitudes. Supplemental light had the same effect at each latitude. The experiments related to sunflower, soybean, perilla, sesame, groundnut and flax.

According to ALEKSEEv (1) the oil percentage of sesame seeds increased as the photoperiod became longer.

FrIEDERICH (2) states that linseed from tropical regions has a lower oil percentage than linseed from temperate zones, but he attributes this to differences in temperature and humidity. High temperatures and drought probably result in rapid ripening, so that the oil content remains low. He does not refer to any difference in daglength conditions.

Prokofjev (4) found that darkening caused no significant differences in oil percentages of opium poppy seed, but his experiment was arranged somewhat differently as he did not darken the entire plant but only the capsules.

Notwithstanding the great importance of the effect of light on the quality of fruits and seeds, to judge from the literature very little fundamental research has been carried out on this subject.

\section{Conclusions}

1. The oil percentage of the seeds of the sesame variety Early Russian is affected by the photoperiod.

2. At illumination periods of 10 to 20 hours the oil percentage increases, at photoperiods of less than 10 hours there is little change in the oil percentage.

3. The oil percentage increases both by daylight and supplemental light, whereas at photoperiods of the same length the percentage is highest at the longest period of daylight.

\section{REFERENCES}

1 Atekseev, A. P.: (Some data on the development and growth of sesame under conditions of varied lengths of the light day). Krasnodar Vsesoiuzn. Nauch. Issled.-Inst. - Maslichn.. i Efiromas lichn. Kul 't Kratk. Otchet o Nauch.-Issled Rabote 1955.

2 Fruederich, J. C. : Mededelingen Vlasinstituut, Wageningen, 9 (1949) 23; 29 (1956) 17.

3 KurNIx, E. : The significance of the photoperiod in plant acclimatization. Kisérl. Közl. 50 (1956) $57-79$.

4 Proxofjev, A. A.: The formation of oil in plants. Usp. Sourem. Biol. (Adv. mod. Biol., Moscow), 39 (1955) 129-153.

5 SMILDE, K. W. : The influence of some environmental factors on growth and development of Sesamum indicum L. Thesis Doct. Agric. Sci., Wageningen, 1960, in press. 